\title{
An Orchestral Audience: classical music and continued patterns of distinction
}

\begin{abstract}
This paper considers the key findings of a yearlong collaborative research project focusing on the audience of the London Symphony Orchestra and their introduction of a new mobile telephone ('app') ticketing system. A mixedmethod approach was employed, utilising focus groups and questionnaires with over 80 participants, to research a sample group of university students. This research develops our understanding of classical music audiences, and highlights the continued individualistic, middle-class, and exclusionary culture of classical music attendance and patterns of behaviours. The research also suggests that a mobile phone app does prove a useful mechanism for selling discounted tickets, but shows little indication of being a useful means of expanding this audience beyond its traditional demographic.
\end{abstract}

Keywords: apps, audiences, Bourdieu, digital, distinction, classical music, class, cultural omnivore

\section{Introduction}

This paper considers the key findings of a yearlong collaborative research project focusing on the audience of the London Symphony Orchestra (LSO) and their introduction of a new mobile telephone ticketing application or 'app'. The app was chiefly introduced to provide an easier and more cost effective way of selling discounted concert tickets to (primarily an already existing) student audience; however, a secondary aim, was that it was hoped that by using technologies (smart phones and apps) popular with a wide young demographic (Bauer et al., 2005) this might also help expand the LSO's current audience base.

Compared with research on other genres of music, such as pop and jazz, there is significantly less empirical research on classical music audience, and even less on the use of new technologies as a means of classical music audience engagement. The aims of the overall research project were therefore two-fold: first, to evaluate the effectiveness of the app as a mechanism for selling discounted student tickets, and secondly to explore its potential for audience expansion and engagement. 
Elsewhere (Crawford et al., forthcoming) we focus more on the social networking potentials of this new technology, and it is also our aim in future publication to focus on the app as a marketing tool. However, significant findings that arose from the research were the continued patterns of class-based social exclusion around attending a live classical music event, and moreover, the desire of the participants in this research to maintain these continued patterns of distinction (Bourdieu, 1984).

This paper begins with a consideration of some of the relevant literature on classical music audiences. There is a significant literature on classical music audiences, which includes (but is not limited to) the work of authors such as, Dobson, (2010), Kolb (2000, 2001a, 2001b), Pitts, (2005), O’Sullivan (2009), Small (1987, 1998). However, here we focus most keenly on discussions concerning patterns of distinction around the live classical music experience. The paper then highlights the 'cultural omnivore' literature (such as Peterson and Kern, 1996), which argues that there has been (to some degree) a loosening of class-based taste hierarchies, as well as the work of authors, such as Savage and Gayo (2011), who seek to counter such arguments; and in particular, it is this counter-omnivore argument that this paper seeks to add increasing weight to.

The paper then considers the methods and some of the key findings of the research. We focus briefly on the nature and reception of the ticketing app, before moving on to discuss in more detail some aspects of the classical music audience and its culture. This paper significantly adds to our understanding of classical music audience, their adaption of a new mobile technology, it offers evidence of continuing patterns of cultural distinction, and adds qualitative data to an area most commonly researched using quantitative methods.

\section{The Classical Music Audience}

Cultural practices are 'automatically classified and classifying, rank ordered and rank ordering' (Bourdieu, 1984: 223), and, for Bourdieu tastes and knowledge of music was one of the clearest indicators of social class. As he firmly stated in Distinction: '...nothing more clearly affirms one's social "class", nothing more infallibly classifies, than tastes in music' (Bourdieu, 1984: 18). In particular, live 
classical music audiences have for some time typically reflected a demographic, which The Guardian journalist Stephen Moss (2007) (drawing on Mintel data) described as: 'a narrow demographic: getting on in years, retired, white [and] middle-class'.

Research in the US, UK and Western Europe has for some time highlighted the middle-class, exclusionary and ritualised nature of live classical music audiences (Bennett et al., 2009). In particular, Small $(1987,1998)$ compares attending classical music to a Catholic mass, which requires attendees and performers alike to follow specific learnt and time-honoured patterns of behaviour. Small suggests that attending a classical music concert operates at two social levels: the first being the surface level of the musical experience, but secondly, at a more fundamental level, where it plays out and reaffirms class cultures and boundaries. As Kolb (2000: 21) wrote 'for traditional audience members, western classical music is seen as an affirmation of the values of middle-class life which includes self-control and hard work'. The classical music repertoire itself became fixed sometime around the First World War, to include a canon of 'great classics' at the expense of anything more contemporary. Small (1998) argues, that during the twentieth century, which saw rapid and fundamental social changes, classical music concerts provided (and continue to) a solid space where the middle-classes can reaffirm their values and place within a social hierarchy. As Bennett et al. (2009: 75) wrote: 'for elite groups...classical music evokes hierarchy and power: the ghostly memories of legitimate cultural capital'.

Inevitably, these patterns of ritualised and learnt behaviour can act as a key barrier to those that are not schooled in the habitus of the classical music field (Bourdieu, 1993). As Kolb (2001b) argues, there is evidence to suggest that listening to recorded classical music crosscuts age, education and ethnic groups; however, audiences at live classical music concerts in both the UK and US remain predominantly well-educated, older and white. In particular, both Kolb (2000) and Dobson (2010) conducted studies where they took a small sample group of individuals who had never been to a classical music concert before, and then interviewed them in focus groups about their experiences. In both cases the research participants highlighted feelings of anxiety concerning their lack of 
knowledge of both the music and also the accepted patterns of behaviour at classical music concerts. The term that Kolb (2000: 17) uses is the research participants' concerns over their lack of 'special knowledge'; which could be theorised as a lack of appropriate 'cultural capital' (Bourdieu, 1984).

\section{The Cultural Omnivore}

While Bourdieu's original thesis may have been an accurate account of cultural practices and distinctions in 1960s France, many have questioned if his findings can still be held as a true reflection of contemporary patterns of cultural tastes and consumption (Atkinson 2011). In particular, the post-Bourdieuian literature on the 'cultural omnivore' (such as, Erickson, 1996; Peterson and Kern, 1996) suggests that there has been a softening of class-based taste distinctions. In particular, a great deal of this research has focused upon music tastes. The cultural omnivore literature suggests that the cultural landscape Bourdieu was describing was one of 'snob versus slob' (Chan and Goldthorpe, 2007:3); where specific cultural tastes could be aligned with particular social classes. For example, Bourdieu suggested that liking of the 'Blue Danube' by Strauss was preferred by manual workers, while Bach's 'Well-Tempered Clavier' was popular with those who had higher levels of cultural capital (Prior, 2011: 126). However, authors such as Peterson and Kern (1996) (and others) suggest that in recent times a diffusion of cultural tastes is occurring, with members of society's elite acquiring more interest in middle and lowbrow tastes, and (to a certain degree) those further down the social spectrum developing tastes in high and low brow culture and middle and highbrow culture respectively. This shift from snobbishness to omnivorousness, Peterson and Kern suggest, is occurring due to a number societal changes. This includes, an increase in educational, geographical and social mobility, generational politics and the liberalisation of culture since the late 1960s, but most notably, the massification of culture, which sees capitalist market forces seeking to sell cultural activities to as wide an audience as possible.

However, it is suggested that this softening of class-based taste distinctions may be most notable at the top of the class hierarchy, and in particular for those with higher levels of education (Coulangeon and Roharik, 2005). That is to say, while 
research data suggests that some traditionally 'popular' ('lowbrow' and 'middlebrow') pastimes may have seen an increase in popularity with middle and upper-class consumers respectively (for example, football in the UK, see King, 1998), there is less evidence of those lower down the social hierarchy adopting interests in traditionally deemed 'highbrow' culture (Van Eijk, 2001). This would therefore suggest that it is the highly educated middle-classes (that is to say, the primary audience for live classical music), who are becoming most notably omnivorous in their cultural tastes.

However, as Atkinson (2011: 170) argues, in recent years 'several authors have begun to register reservations, to flag shortcomings of the research unveiling omnivorousness and to query the conclusions drawn'. This includes Atkinson (2011), along with others, and most notably, the work of academics (then at) the University of Manchester, such as, Warde et al. (1999), Savage and Gayo (2011), who have sought to both challenge and develop a more nuanced understanding of changes in patterns of cultural taste.

For example, Warde et al. (2007) argue that though the basis of the omnivore argument is that there has been a change in patterns of cultural consumption overtime, few studies offer a longitudinal analysis, which could provide supporting evidence for this argument. Warde et al. (2007) therefore suggest, rather than cultural omnivorousness being a new trend, picking and choosing from a 'cultural buffet' (to use Kolb's 2005 description) may simply be what the educated middle-classes have always done. Savage and Gayo (2011: 338) argue that omnivorousness does not straddle different cultural domains, but rather needs to be understood as 'dominant, expert positions, within cultural hierarchies'; and one example they give is of expertise around classical music. Here, they suggest that what marks out middle class taste is the ability (expertise) to pass positive and negative judgments concerning a particular genre or cultural form, such as classical music.

It is therefore in this context that we seek to consider the LSO's student ticketing app. Not only as a mechanism for selling discounted tickets, but also as an avenue to explore a young audiences' attitudes and patterns of attending live classical music and the changing and/or continued cultural configurations of 
distinction surrounding this event.

\section{The Research}

This research was funded through a Digital R\&D for the Arts grant, supported by the AHRC, NESTA and the Arts Council England. The purpose of this grant was to fund cultural organisations to introduce new forms of technology in order to develop new methods of audience engagement and/or new business models. As part of the fund an academic research team was funded to evaluate and feed into the development and implementation of the technology and its role in audience engagement or business development.

This research employed a flexible mixed-method approach to research a primary sample group of (as stipulated in the LSO's original proposal) 18-25 year old university students. Research has shown, time and time again, that audiences for classical music events in the $\mathrm{UK}$, as in many other countries, are primarily educated and middle-class. Therefore, as Kolb (2000: 13) argues, 'university students are a prime future market segment'.

First, and primarily, the key method of data was post-concert focus groups. Focus groups are the main method of data collection employed in the majority of existing studies on classical music audiences, including Kolb (2000), O’Sullivan (2009), Pitts (2005) and Dobson (2010). However, where Kolb and Dobson's research focused primarily on those who had previously never attended a live classical music event, similar to Pitts and O'Sullivan, the aims of our research were more keenly focused on the existing audience.

Focus groups are particularly beneficial as to some extent they mimic social interactions that occur outside of the interview setting. Therefore, a focus group of peers is a useful tool for understanding how music and technologies might be discussed and utilised in a social context. Of course, focus groups are not without their shortcomings, such as the risk of certain individuals dominating discussions, and as Pitts (2005: 259) suggests, there can be a tendency for participants to engage in 'a certain degree of self-presentation'. However, these and other pitfalls, can (to some degree), be addressed by a skilled facilitator (Morgan, 1997). 
In total seven focus groups were held after (or in one case before) LSO concerts at rooms in the concert venue, between February and June 2012. The concerts were selected on the basis that they had discounted tickets available to students. The first two focus groups were held before the app was launched, and the remainder conducted subsequently.

The focus group participants were primarily self-selecting. Students purchasing tickets were emailed and asked if they would be willing to participate and offered a $£ 20$ (GBP) incentive for doing so. The number of participants in the focus groups varied from 10 to 13, with a total sample of 81 students. Given the nature of the sampling used, no claims of statistical representativeness can be made; however, the number of participants in this research is significantly larger than those interviewed in the studies by Kolb (2000), Pitts (2005), O'Sullivan (2009) and Dobson (2010), which each had less than 20 participants, and similarly, utilised non-probability sampling techniques. This is therefore, to date, the largest qualitative study of a classical music audience in the UK.

To complement the focus groups, a short questionnaire was handed out to participants before each focus group and completed by 68 respondents. In addition, observations of the audience were recorded in notebooks by two researchers at the four LSO concerts, and a number of photographs were taken. One-to-one interviews were also conducted with members of the marketing staff at the LSO and the app development team. All interviews were transcribed, thematically coded and systematically analysed by the researchers. What follows is an analysis and discussion of some of the key findings obtained from this research.

\section{The Introduction of the Student Ticketing App}

The student ticketing app replaced an existing mobile SMS (short message service) or 'text message' based student discounted ticketing scheme. With the SMS system student 'ambassadors' were recruited at university fresher's fairs in and around Greater London. Significantly, only certain university fresher's fairs were targeted, and notably they tended to be certain 'top-level' institutions. As the LSO Marketing Manager (on the 10/02/12) stated: 'I just stick to ... you know, UCL, Kings, Imperial, Goldsmiths...'. Once recruited, the ambassadors then 'sold' 
concert tickets to fellow students by replying to SMS prompts from the LSO about forthcoming concerts. For doing so, the ambassadors then received one free concert ticket per transaction.

There were however, several problems with this system. These included: firstly, that the ambassadors were often only buying one ticket, effectively turning this into a 'buy-one-get-one-free' scheme; secondly, the mobile telephone companies took a substantial cut of the ticket costs as a surcharge; and thirdly, a SMS message greatly restricts the amount of interaction or information that can be shared between the LSO and their target audience.

Therefore the primary aim of the app was to easily and cost-effectively sell discounted tickets to an exiting student audience, and incentivise them to attend more often. As the LSO's Digital Marketing Manager stated in interview (04/01/12):

The overall aim for the [new] student scheme is to remove some of the barriers to attendance for students by discounting tickets, incentivising coming as a group of friends and increasing repeat attendance through a structured loyalty scheme...

A secondary hope of the LSO marketing team was that the app might encourage new attendees. As Bauer et al. (2005: 182) argue, mobile telephone apps have a key advantage for advertisers, in that, mobile telephones are popular with young adults, and hence 'lends itself to effective to mobile marketing...'. However, the expansion of the audience was not a goal that was explicitly pursued through the marketing of the app. The app was only advertised via flyers on the student ticket stand at concerts, to the existing ambassadors, and via the existing mechanism of recruiting ambassadors; that is to say, at fresher's fairs at the same top-level universities around Greater London.

\section{The Participants' Profile}

The pre-focus group questionnaires points to a certain class profile of the sample group. Given that all the participants were full-time students, the questionnaire asked the occupational category of their parents/guardians, using the Labour Force Survey classification scale. Of the 32 participants who answered this question $62 \%(n=20)$ of respondents suggested that at least one of their 
parents/guardians were in a 'manager or senior official' occupation and 19\% $(n=6)$ suggested they had one parent/guardian who was in a 'professional' occupation. Though the numbers surveyed here are too small to be statistically significant, the $74 \%$ of respondents with a parent/guardian with a 'manager or senior official' or 'professional' occupation is remarkably higher than the figure for the UK more generally, where these occupations make up only $29 \%$ of the workforce (ONS, 2010). And, though self-declarations of class status are notoriously problematic, $70 \%(n=17)$ of respondents suggested that they were 'middle-class ', and 17\% (n=4) 'upper-class', with only $3(12 \%)$ suggesting they felt themselves to be 'working-class'. Though again the numbers surveyed here are far too small to be statistically significant, they are somewhat different to the $48 \%$ of respondents who declared themselves 'working class' in a 2011 YouGov survey (UK Polling Report, 2011).

Once students have downloaded and signed up for the app it encourages them to become repeat attendees by offering points for purchasing concert tickets, which can be exchanged for gifts. At the point of conducting the research the rewards began with one months' subscription to the online music streaming service Spotify (for 100 points) ranging to an Xbox 360 (for 6000 points). Significantly, the LSO only has a set number of discounted student tickets available per concert (usually around 100) and only for certain concerts. Therefore, the primary aim of the app was not necessarily about increasing overall student audience. The introduction of the app was primarily to ensure that more of the revenue from ticket sales came directly to the orchestra, and to try and encourage current attendees to come more often.

Certainly in its primary aim the student ticketing app appears to have been successful. Data supplied by the app developer indicates that in the first six months of its launch (by August 2012) the app had 265 registered users, and of the 390 discounted tickets that were available to students over the four concerts of the research period (March to July 2012) 318 (82\%) had been sold. This compares with 175 ambassadors who had signed up to the previous SMS-based ticking scheme and $67 \%$ of available discounted tickets sold in the six months prior to the launch of the student ticketing app. 
However, from the focus groups there is little indication that the higher number of app users compared to ambassadors signified a new audience. Of those surveyed only 3 out of 81 indicated that they had previously not been to a concert at the LSO, and one of these had never attended a live classical music concert before. Significantly, none of these first time attendees suggested that the app had played any role in them attending this time, but rather they already had an interest in listening to (recorded) classical music and had been encouraged to come along by a friend who already regularly attended concerts at the LSO. When asked if they felt the app might encourage a new audience, most were sceptical. As comments by Participant 10 in Focus Group 2 (09/02/12) reflect:

FG2P10: If I'm honest I think your target audience is more going to be people...young people who are already interested in [classical] music I don't think you have much chance of um interesting people um into coming to concerts who aren't already interested in [classical] music, because I think that interest comes from a much younger age.

Significantly, many focus group participants questioned whether a classical music orchestra should be trying to attract a new audience at all, as indicated in the comments made in Focus Group 5 (5/04/12):

FG5P5: Does everybody need to listen to classical music, not everyone is into the same thing? I don't know, after football matches do they have focus groups about how to get people to go to football? Not everyone does everything.

This seems counter to Pitts' (2005: 263) research on a Sheffield chamber music audience, which she suggested, appeared keen to 'broaden the age range and social profile of the audience'. To some degree, this might reflect Pitts' focus on a regional (and Northern) audience for chamber music, compared to our research on a metropolitan orchestral music audience.

\section{Mobile Concert Companions}

The focus groups also explored the idea of the app being expanded to provide, not just ticket, listings and venue related information, but also information on the music, orchestra, composers, or similar. This is similar to the idea of the concert companion, which appeared in certain concert halls, most commonly in North America, in the 1990s. Concert companions were hand-held PDA devices, 
which provided information for audiences during the live event - such as translations, notes on the music, composer, conductor, and so forth. However, these kinds of innovations often received somewhat mixed responses. For example, as Brown (2004: 14) highlights, while 'some people really enjoy embedded interpretations in their concerts...others really don't'. And generally the idea that the app could be used as a concert companion was not popular in the focus groups, for two main reasons. First, it was felt that a more visual or mediated experience would distract from the focus of listening to the music. This was articulated by a participant in Focus Group 1 (05/04/12):

FG1P1: I really don't understand this need for people to [have] multiple sources [of sensory stimulation]

And second, the focus group participants emphasised the importance of classical music audiences already possessing an understanding and appreciation of the music. A participant in Focus Group 4 (05/04/12) expressed a typical sentiment here:

FG4P7: ...not everything has to be handed to us on a plate, like I don't see the need.

Hence, a recurrent theme in many of the focus groups was the idea that classical music was not for everyone, and maybe should not necessarily be so. This then raised further questions about the nature of contemporary classical music audiences, the origins of their interests, and patterns of continued exclusion and distinction around live classical music.

\section{Origins of Interest in Classical Music}

As stated by Participant 10 in Focus Group 2 above, the vast majority of participants indicated that their interest in classical music was something that developed at a young age. In particular, supporting the arguments of BoalPalheiros and Hargreaves (2001), by far the two most dominant reasons participants gave for their interest in classical music was the influence of parents or the playing of a musical instrument, which they were encouraged to do, most commonly either at school or (once more) by parents. For example, when asked where their interest in classical music came from, below is a typical comment given by one participant in the Focus Group 1 on 09/02/12: 
FG1P2: Mine was through school so I was playing at school and we'd have lots of school trips because we all played in an orchestra so we'd go on school trips... and to the opera and all sorts of stuff.

Following Atkinson (2011) it is apparent that there are often key figures, such as teachers or parents - 'musical mothers' to use Bourdieu's (1984: 75) language - who played a key role in cultivating an interest in classical music. Hence, this would also seem to support the assertion of classical music as a specific habitus, into which most individuals are inducted and schooled, often at a young age. This is important for future patterns of classical music attendance, for as Kolb (2001a) argues, many tastes acquired when young do not change significantly as we get older.

\section{Patterns of Appropriate Behaviour}

The idea of being schooled into a classical music habitus, one which embodies aspects of practical consciousness, and norms and rules of conduct (Shove et al., 2012), is further supported by participants' comments on patterns of 'appropriate' behaviour at the live music event and their understanding of classical music. All those in the focus groups who commented on this subject indicated that classical music attendance did have recognisable patterns of acceptable behaviour, which they had to learn. Concert halls, like restaurant or theatres, have elements of both the public and private; in that they are shared spaces occupied (in close proximity) by strangers (Ling 1997). However, audiences commonly engage in what Goffman (1963) has referred to as a 'civil inattention'. Here, people in a shared social space acknowledge others' presence, but construct fictive barriers. However, civil inattention is only maintained while social actors play their expected social roles, and deviating from this is likely to result in social sanctions. This is highlighted in the excerpt from Focus Group 6 (21/05/12) concerning clapping at 'inappropriate' times:

FG6P1: You only make the mistake of clapping when you shouldn't once [laughter]

FG6P2: And we've all done it as well.

FG6P1: The experience of being the one person clapping when there's 800 other people not clapping... and you know the people around you are glaring at you out the corner of their eyes. 
However, persistent or more serious cultural infringements can lead to direct confrontation. For example, a participant in Focus Group 6 (21/05/12) highlights how audience members can play an overt role in policing patterns of 'appropriate' behaviour:

FG6P2: It's funny you mention that, because tonight I was seated behind this young couple and at the beginning of the concert they were very lovey-dovey, and I was also right next to...this...older lady, who obviously attends classical...I mean she was dressed to the nines and everything, and when they were doing that [being 'lovey-dovey'] within like, the first three minutes, she like tapped the girl's shoulder and she was like 'no' [laughter].

Social sanctions themselves follow well-rehearsed and expected patterns of response and escalation, further highlighting the structured nature of social spaces; or 'fields' in Bourdieu's terminology. In the case of the classical music concert hall then, these regimented patterns of behaviour further support Small's $(1987,1998)$ arguments concerning the ritualised nature of classical music. As Geertz (1972: 290) argues, the higher one goes up the social ladder 'the thicker the wall of etiquette protecting social life'. Though Pitts (2005: 265) research on a Sheffield chamber music audience does suggest less formality for both the audience and performers, even here, she noted a 'strong resistance to change' in terms of 'the ethos and standards that are valued by regular attenders'.

\section{Understanding and Appreciation of Classical Music}

Unlike patterns of behaviour, where participants were much more willing to ascribe this to tuition and observation, the language used in describing their understanding and appreciation of music was often somewhat different; relying more on terms such as the need to have good 'concentration', 'understanding' or 'intellectual' engagement. For example, when participants were asked where their understanding of classical music comes from, a typical response was given in Focus Group 1 (09/01/12):

FG1P1: I think...with classical music you need some kind of...you need to be able to kind of invest intellectually, it's not pop

Similar comments could be heard in the other focus groups, such as in Focus Group 4 (05/04/12): 
FG4P1: I suppose that's a big difference compared with pop or other types of music, in that, you actually need to be able to concentrate for an extended period of time, whereas I think that emphasis is completely missing in other genres [emphasis added]

This is similar to Pitts' (2005: 267) findings, which suggest that participants in her research were most keen to emphasise their skills as 'an appreciative listener' or an 'accomplished listener', for example.

Some focus group participants sought to emphasise that appreciation of classical music operated at a more fundamental and emotional level. However, the assertion here would appear to be again that those who do not like classical music do not share the same fundamental and deeper appreciation of the music. Similar to the findings of Bourdieu (1984), in relation to middle-class patterns of taste, it appears that participants in this research were less willing to attribute their understanding and appreciation of classical music to tuition, instead emphasizing that it stems from either a deeper intellectual or emotional engagement. However, this was not the case for first time attendees, such as a participant from Focus Group $4(05 / 04 / 12)$, who indicated that he was lacking an 'education' in how to understand and appreciate classical music:

FG4P3: ...what you were saying before about sort of understanding classical music that's what I think I'm missing. I'm not really that aware of what's actually going on so much. I'd appreciate some education on that...how I should go about listening to classical music to really get the full experience.

\section{Perceived Differences between Classical and Pop Music}

The importance of a deeper 'intellectual' or 'emotional' engagement with music was a theme that frequently appeared in discussions around the differences between classical and pop music in some of the focus groups. As this exchange from Focus Group 4 (05/04/12), involving the first time attendee (FG4P3) from above, illustrates:

FG4P1: It's [pop music] the most inane bullshit [laughter]. If you want someone telling you the most ridiculous things that just passes across the stream of consciousness then listen to mainstream music, I really fail to see the intellectual insight that music offers, but...

FG4P3: It's good for clubbing

FG4P1: It's not an intellectual type of thing. 
FG4P3: It's got a time and a place.

FG4P1: A pretty limited one at that.

Similar comments, in relation to the lack of depth and level of engagement offered by pop music were made in other focus groups. Such as the comments made in Focus Group 5 (05/04/12):

FG5P1: It's [pop music] just wallpaper, noise that people have on all the time. I prefer to listen to music and not have it as background music.

In many ways this reflects Adorno's (1941) argument that 'serious' music needs to be intellectually engaging, an argument challenged by his contemporary Walter Benjamin (1968) in his consideration of listening to jazz music in a state of 'distraction'. This is also an argument discussed further by Bourdieu (1984, 1990) who highlights that an intellectualised appreciation, as opposed to consumption for personal enjoyment, is a key mechanism of elitist and exclusionary cultural capital. As Coulangeon and Roharik (2005:2) argue, Bourdieu's thesis is as much about cultural distaste as it is taste:

In the music field, the 'dominant' (i.e. the taste of the dominant class) is in this way defined as an unambiguous penchant for highbrow genres (classical, opera, contemporary classical) and an equally pronounced rejection of lowbrow or commercial genres.

Furthermore, arguments or disagreements over what are legitimate musical tastes should not necessarily be seen as a softening of cultural hierarchies. As Prior (2008: 304) highlights, it is conflicts over the nature of a field that help define it.

However, though several respondents were keen to highlight the intellectual distinctions between classical and pop music, it appears that a sizable number of participants did still regularly listen to genres of pop music. A good proportion of respondents (62\%) stated that they regularly (more than several times a week) listened to recorded 'rock-pop/indie' music, not far behind the percentage (74\%) who indicated they regularly (more than several times a week) listened to recorded 'classical music'. With almost half (40\%) listening to 'commercial/chart pop' music, 29\% 'hip-hop/rap', and 28\% 'electro-pop/dance', more than several times a week. Hence, in terms of their listening patterns and musical tastes, many of the participants did seem quite omnivorous. However, as Chan and 
Goldthorpe (2007) highlight, what is significant is not only what is consumed, but also how it is consumed. As they write:

Omnivores may still show discrimination, either in the uses that they make of mass or popular culture - e.g. often 'ironic' or otherwise condescending uses - or in still rejecting some of its particular forms, such as ones with an especially close association with low-status groups (Chan and Goldthorpe 2007: 3)

The above exchange (set out earlier) between Participants 1 and 3 in Focus Group 3 was typical of how popular music was most commonly discussed in the focus groups, or along the lines of Participant 12's comments in Focus Group 7:

FG7P12: I listen to some mainstream music, but it's mainly electronic dance music. Music that's got something...something creative in it...not like $X$ Factor or any of that type of stuff.

Only certain types of popular music were seen as acceptable and often only at certain times and locations, such as listening to dance music in night clubs. As Bennett et al. (2009) highlight, the majority of studies of music and class tend to be quantitative, and hence, this is an important point often lost in quantitative studies of consumer patterns. An interest or even propensity to consume a particular item, practice or genre, does not necessarily reveal how this is consumed or why? And more in-depth qualitative research, as in this case, can reveal persistent patterns of distinction hidden behind participation rates. Certainly, our findings would seem to counter Chan and Goldthorpe's (2007: 14) conclusions that 'symbolic' struggles over the legitimacy and value of cultures, 'as advanced by Bourdieu and his followers... is out of place [in] the contemporary world'. In many respects, our research would seem to support Savage and Gayo (2011) in terms of cultural 'expertise'. Our sample would appear to represent what they term 'classical enthusiast', who demonstrate knowledge and expertise of classical music, but also able to extend this to certain other (specific) music genres, which they deem worthy of their attention.

\section{Catering to a Younger Audience}

Some focus group participants made similar assumptions to writers such as Brown (2004), Pitts (2005), and Dobson (2010), that a younger audience more accustomed to pop music concerts may have different expectations, and in 
particular, expect a more social, participatory and multi-sensory experience. Such as the comments of one participant in Focus Group 7 (21/05/12):

FG7P1: Sometimes I have a feeling that [other] young people need to have all senses working, so only hearing is not enough for them, so they are bored... So the cinema is great, because sometimes you just wait for the story to go on and you see something and you hear something and so that's okay for everybody. But a [classical music] concert you just listen, sometimes you can see and watch, but I think just to listen and to be quiet... they can't do it any more in this society....

This is a point similar to that made by Participant 1 in Focus Group 1 cited earlier in the paper, that is to say, that to require a variety of stimulation suggests that the audience is somehow less capable - that they lack the ability to 'just ...listen and to be quiet' (FG7P1). This regimentation and control of the body is an important aspect and affirmation of middle-class culture, and very evident at the classical music concert (Small, 1998).

\section{The Individual Nature of the Classical Music Concert}

In line with another key middle-class value, and similar to O'Sullivan (2009), our research found that many of our respondents sought to emphasise the individualistic, rather than the collective, experience of attending a classical music concert. As reflected in comments from Focus Group 1 (09/02/12):

FG1P4: I'd say it's [the live classical music concert] quite an individual experience to me that's why I prefer maybe sometimes going on my own because it just makes me feel in my own world and you don't have to share it. It's not a social experience to me.

However, despite this, as O'Sullivan (2009) and Pitts (2005) also highlight, part of the experience that individuals seek at a classical music concert is feeling part of a community, and knowing that others are experiencing the same as them. As Participant 4 from Focus Group 4 (05/04/12) commented:

FG4P4: ...some bits in the music what you're experiencing you know that every single other person almost is going to be feeling the same way. So you can look around and see people's reaction and you know they're going to be sort of similar. For instance the first movement here you look around and you see everyone just like... I guess it's personal but everyone is feeling the same as well.

O'Sullivan (2009) suggests that even though many seek to emphasise the 
individualistic nature of the live classical music experience, part of the appeal of attending a classical concert seemed to be a sense of community. As writers such as Bauman (1992) and Maffesoli (1996) argue, in a late-modern world, a dual and conflicting pull becomes ever-present in our everyday lives. As consumption and leisure become increasingly individualised and privatised, individuals feel a loss of community and wider social belonging. Hence, leisure interests are often shaped by a desire to seek community, belonging and stability in an increasingly privatised, unstable and liquid world, and because of this, people seek temporary belonging in interest-based communities. As Small (1998) argues, in many respects, classical music offers this to its middle-class patrons: a sense of stability, and an individualised and ritualised celebration of middle-class values, surrounded by 'people like us', all doing the same.

\section{Connecting with Classical Music in Everyday Life}

These tensions between individual and collective consumption can also be seen away from the live music venue. The majority of participants in the focus groups stated that classical music was an important part of their cultural life, and as with Pitt's (2005) research, most indicated regularly listening to recorded classical music. However, all stated that it was not something they would generally discuss with others. Again, the need to have understanding and appreciation of classical music was raised as a common reason why people did not discuss this more often. Such as the comments made by a participant in Focus Group 1 (09/02/12):

FG1P6: I think it would be quite difficult to talk about music to someone ...it's uh so complex that I don't know what you would really talk about to someone who has no understanding of classical music. You would have nowhere really to start to talk about a particular piece or anything so it would be quite difficult.

Though Bennett et al. (2009: 92) suggest that 'classical music remains important to elite groups for providing appropriate connections', it seems that these connections are most common in-group (bonding) rather than outward facing (bridging) (see Putman 1995). And certainly in these focus groups there was evidence of exclusivity around discussing classical music.

The findings from this research do seem to support the work of authors such as 
Small (1998) and Kolb (2000), as well as the wider sociological literature of Bourdieu (1984) and others on cultural distinction, which emphasise the ritualised and middle-class nature of classical music attendance; which Kolb (2000: 21) describes as 'an affirmation of the values of middle-class life'. However, it is important that social class is not seen as an independent variable. That is to say, we cannot simply say that a person's social class will determine their cultural interests, such as a fondness for classical music. As Ollivier et al. (2009) (following Bourdieu) argue, a person's social class is an aggregate of a number of symbolic and behavioural, as well as, material factors. That is to say, just as social class may help determine, for example, interests and behaviour, in turn, interests and behaviour also determine social class. Hence, it is not simply that it is the middle-classes who primarily attend classical music, but also, that classical music helps make and maintain who and what the middle-classes are. However, as Shove et al. (2012) note it must be acknowledged that those who have the means to engage in cultural practices that are 'valued' are in a privileged position, as it is they who are most likely to contribute to how those practices develop.

\section{Conclusion}

Research has time and time again shown that classical music audiences in the UK, as well as in many other regions such as North America, reflects 'a narrow demographic: getting on in years...white [and] middle-class' (Moss, 2007: np). Given that the majority of classical music attendees in the UK are university educated, current university students therefore provide a key target market for orchestras like the LSO.

From research conducted with a sizable sample of the student audience at the LSO, this research suggests that this audience does appear welcoming of a (limited) role of new technology in facilitating their access to live classical music. The chief aim of the LSO's student ticketing app was to sell discounted tickets to, predominantly their current audience, of students in a simple and cost effective way. So, in this respect, the technology appears to have been successful. More students were signed up for this scheme, and purchasing more tickets, than the 
previous SMS-based mechanism. However, beyond this, the research has highlighted key and continued patterns of distinction and exclusion.

The focus group participants emphasised that an understanding of patterns of behaviour, knowledge and appreciation of the music at the live classical music event are important and necessary pre-requisites to attendance. And sentiments were often expressed that this should not be 'dumbed down' (such as through the use of concert companions) in order to simply attract a wider audience. This research found no evidence to suggest that a younger audience would want a more interactive and participatory experience in their live music attendance. As well as the respondents' aversions to the use of new interpretative and interactive technology in the live concert venue, the majority also sought to emphasise the individualistic nature of the live classical music experience.

Hence, though this research finds evidence to suggest that this sample group did frequently listen to a wide range of music types and genres, there is little evidence to support a more general shift from 'snobbishness' to 'omnivorousness'. It seems that this particular sample group, have broad music tastes and are happy to embrace new technologies when it facilitates their access to live classical music; however, they appear to remain persistently 'snobbish' in their attitudes towards classical music appreciation and patterns of appropriate behaviour at the live classical music concert.

The cultural omnivore literature highlights the massification of culture as a major contributor to the rise of omnivorousness. But it is important to remember that not all cultural practices are massified. Attending live classical music, certainly in this case, seems to constitute a relatively small and narrow demographic, which neither the audience nor the orchestra seem particular motivated to significantly expand. In this sense, live classical music provides a safe and solid venue for the continuation and affirmation of middle-class values, practices and habitus.

\section{Acknowledgements}

This project was funded as part of the Digital R\&D Fund for the Arts, supported by the AHRC, NESTA and the Arts Council England. We would also like to thank 
the London Symphony Orchestra, their marketing team, their audience, and the app developers, Kodime Ltd., for their cooperation throughout this research.

\section{References}

Adorno, T. (1941) 'On Popular Music', Studies in Philosophy and Social Science, New York: Institute of Social Research, IX, 17-48

Atkinson, W. (2011) 'The Context and Genesis of Musical Tastes: omnivorousness debunked, Bourdieu buttressed', Poetics, 39, 169-186.

Bennett, T., Savage, M., Silva, E., Warde, A., Gayo-Cal, M. \& Wright, D. (2009) Culture, Class, Distinction, London: Routledge.

Benjamin, W (1968) Illuminations: essays and reflections, New York: Schocken Books.

Bauer, H.H., Barnes, S.J., Reichardt, T., \& Neumann, M.M., (2005) 'Driving Consumer Acceptance of Mobile marketing: a theoretical framework and empirical study', Journal of Electronic Commerce Research, 6(3): 181-191.

Bauman, Z. (1992) Intimations of Postmodernity. London: Routledge.

Bourdieu, P. (1984) Distinction: A Critique of the Judgement of Taste, London: Routledge.

Bourdieu, P. (1990) Photography: a middlebrow art, Cambridge: Polity.

Bourdieu, P. (1993) The Field of Cultural Production, Cambridge: Polity.

Brown, A. (2004b) 'Smart Concerts: orchestras in the age of entertainment', Knight Foundation Issues Brief Series No. 5.

Chan, T.W \& Goldthorpe, J.H (2007) 'Social Stratification and Cultural Consumption: music in England', European Sociological Review, 23(1): 1-19.

Coulangeon, P. and Roharik, I. (2005) "Testing the "Omnivore/Univore" Hypothesis in a Cross-National Perspective. On the social meaning of eclecticism in musical tastes in eight European countries', paper presented at Summer meeting of the ISA RC28, UCLA, 19/08/2005. Online: http://cfs.ccpr.ucla.edu/publications/conference-proceedings/CP-05032.pdf (accessed 01 June 2013).

Crawford, G., Gosling, V.K., Bagnall, G., \& Light, B., (forthcoming) 'Is there and app for that? A Case Study of Classical Music Audience Engagement through Digital Mobile Media', Information, Communication \& Society

Dobson, M.C. (2010) 'New Audiences for Classical Music: the experience of nonattenders at live orchestral concerts', Journal of New Music Research, 39(2): 111-124.

Boal-Palheiros, G. M. \& Hargreaves, D. J. (2001) 'Listening to music at home and at school', British Journal of Music Education, 18(2): 103-118

Erickson, B. (1996) "Culture, Class and Connections", American Journal of Sociology, 102: 217-251.

Geertz, C. (1973) The Interpreation of Culture, New York: Basic.

Goffman, E. (1963) Behavior in Public Place, New York: Free Press.

King, A. (1998) The End of the Terraces, Leicester: Leicester University Press.

Kolb, B.M (2000) 'You Call This Fun? Reactions of young, first-time attendees to a classical concert', in D. Weissman (ed.), Music Industry Issues and Studies, 1 (1), Music \& Entertainment Industry Educators Association. New Orleans, Loyola University Press: 13-28

Kolb, B.M (2001a) 'The effect of generational change on classical music concert 
attendance and orchestras' responses in the UK and US', Cultural Trends, 11(41): 1-35.

Kolb, B.M (2001b) 'The decline of the subscriber base: A study of the Philharmonia Orchestra audience', International Journal of Arts management, 9(2): 51-59.

Kolb, B.M (2005) Marketing for Cultural Organisations: new strategies for attracting audiences to classical music, dance, museums, theatre and opera ( $2^{\text {nd }}$ Ed.). London: Thompson Learning.

Ling, R. (1997) “'One Can Talk About Common Manners!”: the use of mobile telephones in inappropriate situations', Themes in Mobile Telephony Final Report of the COST 248 Home and Work Group. Online:

http://richardling.com/papers/1997_One_can_talk_about_common_manners .pdf (accessed 01 June 2013)

Maffesoli, M. (1996) The Time of the Tribes: The Decline of Individualism in Mass Society. London: Sage.

Morgan, D.L (1997) Focus Groups as Qualitative Research, London: Sage.

Moss, S. (2007) 'People will find their own way to it', The Guardian, 5 October 2007. Online:

http://www.guardian.co.uk/music/2007/oct/05/classicalmusicandopera1 (accessed 01 October 2012)

Office of National Statistics (2010) Labour Force Survey Employment status by occupation, April - June 2010. Online:

http://www.ons.gov.uk/ons/publications/re-referencetables.html?edition=tcm\%3A77-239376 (accessed 01 June 2013)

Ollivier, M., Gauthier, G., Truong, A.H. (2009) 'Cultural Classifications and Social Divisions: a systematic approach', Poetics, 37: 456-473.

O'Sullivan, T.J. (2009) 'All together now: a classical music audience as a consuming community', Consumption, Markets and Culture, 12(3): 209-223.

Peterson, R. \& Kern, R. (1996) 'Changing Highbrow Taste: From Snob to Omnivore', American Sociological Review, 61: 900-907.

Pitts, S.E. (2005) 'What makes an audience? Investigating the roles and experiences of listeners at a chamber music festival', Music and Letters, 86 (2), pp. 257-269.

Prior, N. (2008) 'Putting a Glitch in the Field: Bourdieu, Actor Network Theory and contemporary music', Cultural Sociology, 2(3): 301-319.

Prior, N. (2011) 'Critique and Renewal in the Sociology of Music: Bourdieu and beyond', Cultural Sociology, 5(1): 121-138.

Putman, R. (2000) Bowling Alone: the collapse and revival of American community, New York: Simon and Schuster.

Savage, M. and Gayo, M. (2011) 'Unravelling the Omnivore: a field analysis of contemporary music tastes in the United Kingdom', Poetics, 39, 337-357.

Shove, E., Pantzar, M. \& Watson, M. (2012) The Dynamics of Social Practice: Everyday Life and how it Changes, London: Sage

Small, C. (1987) 'Performance as Ritual: sketch for an enquiry into the true nature of a symphony concert', in A.L White (ed.) Lost in Music: culture, Style and the musical event. London: Routledge, 6-32.

Small, C. (1998) Musicking: the meaning and performing and listening. London: Wesleyan University Press. 
UK Polling Report (2011) YouGov Fairness Polling. Online:

http://ukpollingreport.co.uk/blog/archives/3500 (accessed 01 June 2013)

Van Eijck , K. (2001) 'Social Differences in Musical Taste Patterns', Social Forces, 79 (3): 1163-1184.

Warde, A., Martens, L. \& Olsen, W. (1999) 'Consumption and the Problem of Variety: Cultural Omnivorousness, Social Distinction and Dining Out', Sociology, 33(1), 105-127.

Warde, A. Wright, D. \& Gayo-Cal, M. (2007) 'Understanding Cultural Omnivorousness: or the myth of the cultural omnivore', Cultural Sociology, $1(2), 143-164$ 